\title{
Adverse drug events affecting medication persistence with rivastigmine patch application
}

This article was published in the following Dove Press journal:

Patient Preference and Adherence

\author{
Takashi Osada' \\ Norio Watanabe' \\ Naomitsu Asano ${ }^{2}$ \\ Yuzo Adachi² \\ Keiko Yamamura' \\ 'Clinical Pharmacy, School of \\ Pharmacy, Aichi Gakuin University, \\ Nagoya, Aichi, Japan; ${ }^{2}$ Sasayuri \\ Pharmacy, Toki, Gifu, Japan
}

Correspondence: Takashi Osada Clinical Pharmacy, School of Pharmacy, Aichi Gakuin University, Nagoya, Aichi, Japan

Email t-osada@dpc.agu.ac.jp
Purpose: The rivastigmine transdermal patch, the only existing cholinesterase inhibitor available as a transdermal delivery system for treating Alzheimer's disease, has been reported to inhibit progression of cognitive impairment and impairment in activities of daily living, in addition to reducing care burden and improving adherence. However, application of the rivastigmine patch also frequently results in erythema, pruritus, contact dermatitis, and other cutaneous adverse events at the application site, making it difficult to increase the effective dose and continue treatment. Therefore, we conducted a survey to examine the manifestation of adverse events and medication persistence in patients who were prescribed the rivastigmine patch.

Participants and methods: Three hundred and twelve patients diagnosed with Alzheimer's disease between July 1, 2011 and March 31, 2015 at the Toki Medical Clinic and who were prescribed a rivastigmine patch at the Sasayuri Community Pharmacy were involved in the study. Outcomes such as manifestation of adverse events, dose at manifestation, and dose reduction as well as discontinuation were retrospectively examined through medication counseling records.

Results: Adverse drug events developed in 209 of the 312 patients (67.0\%). Approximately $70 \%$ of patients who developed adverse events did so before reaching the maintenance dose of $18 \mathrm{mg}$. The main adverse drug events were cutaneous reactions at the application site such as rash and erythema in 186 patients (59.6\%) and gastrointestinal disorders such as nausea, vomiting, and diarrhea in 29 patients $(9.3 \%)$. Also, of the 312 patients, 118 patients $(37.8 \%)$ discontinued the rivastigmine patch; reasons for discontinuation included cutaneous application site reactions in 74 patients $(62.7 \%)$, gastrointestinal disorders in 5 patients $(4.2 \%)$, and psychiatric disorders in 6 patients $(5.1 \%)$. Among the 74 patients who discontinued the rivastigmine patch due to application site disorders, the dose at the time of discontinuation was $4.5 \mathrm{mg}$ in 22 patients (29.7\%), $9 \mathrm{mg}$ in 37 patients (50.0\%), $13.5 \mathrm{mg}$ in 10 patients $(13.5 \%)$, and $18 \mathrm{mg}$ in 5 patients $(6.8 \%)$.

Conclusion: Approximately $60 \%$ of patients who used the rivastigmine patch developed application site reactions, suggesting difficulty in increasing the dose to the effective dose and in continuing application. Also, $\sim 80 \%$ of the patients who discontinued the rivastigmine patch due to application site reactions developed these reactions when the dose was increased to $9 \mathrm{mg}$.

Keywords: rivastigmine patch, application site reactions, medication persistence, community pharmacy, Alzheimer's disease

\section{Introduction}

The number of people in Japan aged 65 years or older in 2016 was 34.59 million, accounting for $27.3 \%$ of the overall Japanese population. In 2012, the number of Alzheimer's disease (AD) patients aged 65 years or older was 4.62 million; in 2025, the number is projected to be $\sim 7$ million. ${ }^{1} \mathrm{AD}$ is defined as a continuous decline 
in previously normal cognitive function and inhibition of daily and social activities as a result of acquired brain dysfunction. ${ }^{2}$ In Japan, 3 acetylcholine esterase inhibitors (donepezil hydrochloride, galantamine hydrobromide, and rivastigmine) and an $N$-methyl-D-aspartate receptor antagonist (memantine hydrochloride) have been approved for $\mathrm{AD}$ treatment. ${ }^{3,4}$

The rivastigmine patch is the only existing transdermal delivery system used for treating AD. It has been reported to be effective for patients who have difficulty using oral preparations due to risk of aspiration pneumonia. ${ }^{5}$ However, the rivastigmine patch is also associated with a high incidence of erythema, pruritus, contact dermatitis, and other cutaneous reactions at the application site. Adverse drug events (ADEs) in a Japanese clinical trial included application site erythema (43.1\%), application site pruritus $(40.2 \%)$, contact dermatitis (29.0\%), application site edema (13.9\%), and application site skin exfoliation (6.1\%). ${ }^{6}$ Although the developmental mechanism involved in cutaneous reactions at the rivastigmine patch application site has not been determined, it has been suggested that rivastigmine may increase levels of acetylcholine in neurons at the application site, resulting in dilation of the surrounding blood vessels and manifestation of erythema. ${ }^{7}$

In Japan, community pharmacists play a role not only in dispensing medicine by prescription but also in intervention to the reductions in ADEs. As part of their professional role, community pharmacists are expected to contribute more to the appropriate use of medication by patients.

There has been no report of the effects of cutaneous ADEs on increasing rivastigmine patch dose to the effective dose or on medication persistence. Therefore, in order to examine the effects of ADEs on medication persistence, we retrospectively examined the manifestation of ADEs associated with rivastigmine patch application and medication persistence with application among patients for whom the transdermal patch was dispensed by a community pharmacy following a diagnosis of AD by their primary care physician.

\section{Participants and methods Participants}

The participants included in this study were 312 patients diagnosed with AD between July 1, 2011 and March 31, 2015 at the Toki Medical Clinic and who were dispensed rivastigmine patch at the Sasayuri Community Pharmacy. All patients were of Japanese descent.

\section{Clinical characteristics}

Three pharmacists conducted a retrospective study using pharmacist's medication instruction records obtained from the Sasayuri Community Pharmacy. The following outcomes were examined: age, sex, drug name, date of initial use, date of final use, maximum dose, maintenance dose, manifestation of adverse events and dose at manifestation, dose reduction and reason for dose reduction, discontinuation and reason for discontinuation, dose at discontinuation, and concomitant drugs.

According to the information for approved drugs in Japan, treatment with the rivastigmine patch starts at $4.5 \mathrm{mg}$ (contained patch $2.5 \mathrm{~cm}^{2}$ ), and its dose should be increased by $4.5 \mathrm{mg} / \mathrm{d}$ at 4 -week intervals up to the effective dose of $18.0 \mathrm{mg}$ (contained patch $10.0 \mathrm{~cm}^{2}$ ). Dose titration of rivastigmine patch in Japan is shown in Figure 1.

When patients have visited to the community pharmacy to receive prescribed medications, community pharmacists check their medication use, as well as physical and mental

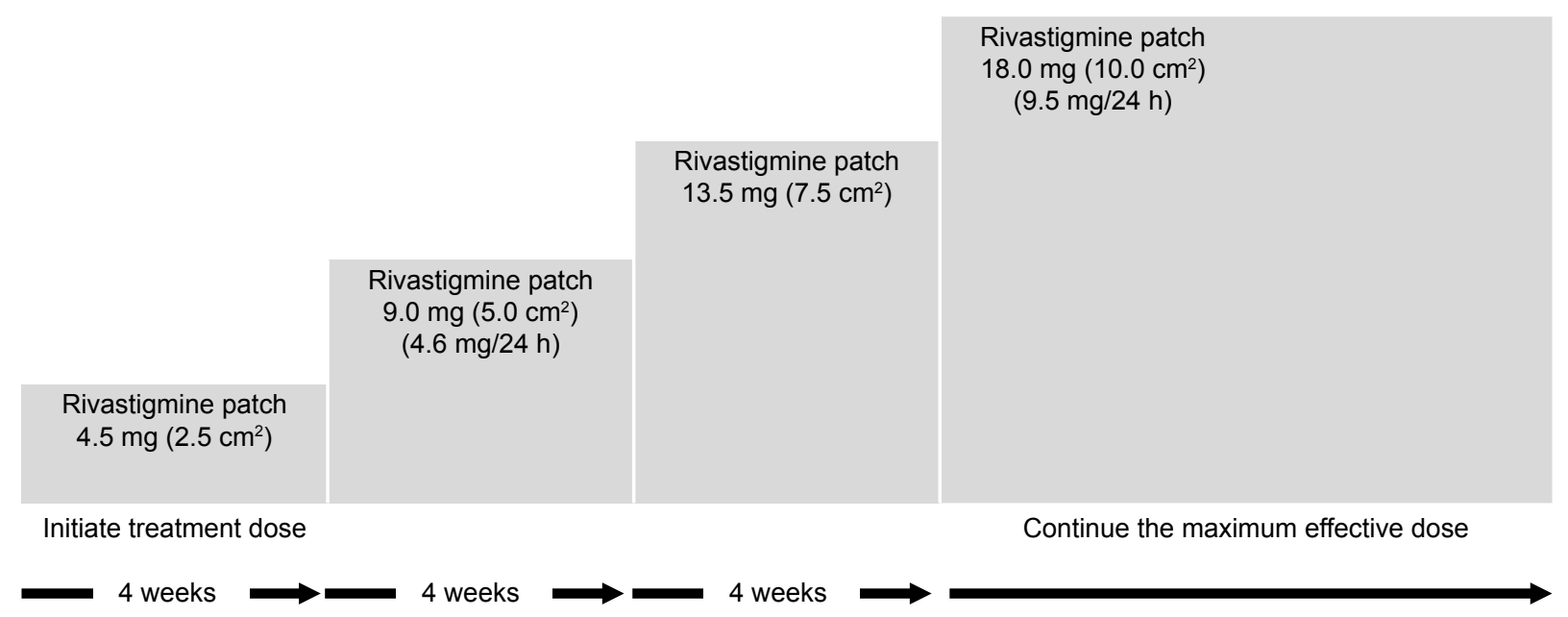

(Patch size: $4.5 \mathrm{mg}=2.5 \mathrm{~cm}^{2}, 9.0 \mathrm{mg}=5.0 \mathrm{~cm}^{2}, 13.5 \mathrm{mg}=7.5 \mathrm{~cm}^{2}, 18.0 \mathrm{mg}=10.0 \mathrm{~cm}^{2}$ )

Figure I Dose titration of rivastigmine patch in Japan. 
problems. Pharmacists recorded the patient's problems and concerns to the pharmacist's medication instruction records, and then inform the prescriber about these.

Physicians at Toki Medical Clinic prescribed steroid hormone-containing ointments and/or decreased the applied rivastigmine dose when diagnosing ADEs. ADEs were standardized using the Medical Dictionary for Regulatory Activities terminology. They were indicated by the preferred term unless otherwise specified. The rivastigmine patch was discontinued for a given patient if the physician determined that continuation of the treatment would result in a significant safety risk for that patient based on safety assessment, including ADEs and abnormal laboratory values.

\section{Ethical considerations}

This study was conducted with the approval of the Aichi Gakuin University School of Pharmacy Clinical Research Institutional Review Board (approval number 53). The Aichi Gakuin University School of Pharmacy Clinical Research Institutional Review Board waived patient informed consent, as all data were deidentified.

\section{Results}

\section{Patient backgrounds}

The study involved 312 patients (male: 87 , female: 225 ) with a mean age of $82.0 \pm 6.0$ (male: $80.6 \pm 6.2$; female: $82.5 \pm 5.8$ ) years. Patient backgrounds are shown in Table 1.

\section{Frequency of adverse events}

ADEs occurred in 209 of the 312 patients (67.0\%). Table 2 shows the frequency of ADEs by category. Cutaneous application site reactions (eg, rash, erythema) occurred in 186 patients $(59.6 \%)$, gastrointestinal disorders (eg, nausea, vomiting, diarrhea) occurred in 29 patients (9.3\%), metabolic/ nutritional disorders (eg, anorexia) occurred in 7 patients (2.2\%), psychiatric disorders (eg, restlessness, aggression) occurred in 15 patients $(4.8 \%)$, nervous system disorders

Table I Background of patients administered rivastigmine

\begin{tabular}{llll}
\hline Age & Male & Female & Total \\
\hline $\begin{array}{l}60-69 \text { years } \\
(\text { mean } \pm \text { SD) }\end{array}$ & $5(65.2 \pm 2.5)$ & $3(67.0 \pm 2.2)$ & $8(65.9 \pm 2.5)$ \\
$\begin{array}{l}70-79 \text { years } \\
(\text { mean } \pm \text { SD) }\end{array}$ & $29(76.1 \pm 2.6)$ & $64(76.1 \pm 2.6)$ & $81(76.1 \pm 2.6)$ \\
$\begin{array}{l}80-89 \text { years } \\
(\text { mean } \pm S D)\end{array}$ & $48(83.9 \pm 2.5)$ & $134(84.2 \pm 2.6)$ & $167(84.1 \pm 2.6)$ \\
$\geq 90$ years & $5(90.6 \pm 0.5)$ & $22(93.1 \pm 2.4)$ & $26(92.7 \pm 2.4)$ \\
$(m e a n \pm S D)$ & $87(80.6 \pm 6.2)$ & $225(82.5 \pm 5.8)$ & $312 *(82.0 \pm 6.0)$ \\
\hline $\begin{array}{l}\text { Total }(\text { mean } \pm S D) \\
\text { Note: } * \text { All patients of Japanese decent. }\end{array}$ & &
\end{tabular}

Table 2 Frequency of ADEs due to rivastigmine in patients with $\operatorname{AD}(n=3 \mid 2)$

\begin{tabular}{lllll}
\hline Category of ADEs & Male & Female & Total & $\begin{array}{l}\text { Frequency } \\
\text { of ADEs }^{\mathbf{a}} \text { (\%) }\end{array}$ \\
\hline Cutaneous application site & 54 & 132 & 186 & 59.6 \\
reactions & & & & \\
Gastrointestinal disorders & 7 & 22 & 29 & 9.3 \\
Metabolic/nutritional disorders & $\mathrm{I}$ & 6 & 7 & 2.2 \\
Psychiatric disorders & 7 & 8 & $\mathrm{I} 5$ & 4.8 \\
Nervous system disorders & 2 & 2 & 4 & 1.3 \\
Hallucinations & 0 & $\mathrm{I}$ & $\mathrm{I}$ & 0.3 \\
Other symptoms & 0 & 2 & 2 & 0.6 \\
Total & $6 \mathrm{I}$ & $\mathrm{I} 48$ & 209 & 67.0
\end{tabular}

Note: ${ }^{\text {With }}>$ I manifestation.

Abbreviations: AD, Alzheimer's disease; $A D E$, adverse drug event.

(eg, dizziness, headaches) occurred in 4 patients $(1.3 \%)$, hallucinations occurred in 1 patients $(0.3 \%)$, and other symptoms occurred in 2 patients $(0.6 \%)$.

Among the 209 patients who developed ADEs, the dose of rivastigmine at the time of onset was $4.5 \mathrm{mg}$ in 42 patients $(20.1 \%), 9 \mathrm{mg}$ in 72 patients $(34.4 \%), 13.5 \mathrm{mg}$ in 32 patients (15.3\%), and $18 \mathrm{mg}$ in 63 patients (30.1\%) (Table 3 ).

\section{Reasons for discontinuation}

Rivastigmine patch application was discontinued within 168 days of initial application by 118 of 312 patients $(37.8 \%)$. The main reasons for discontinuation were cutaneous application site reactions in 74 patients $(62.7 \%)$, gastrointestinal disorders in 5 patients (4.2\%), psychiatric disorders in 6 patients $(5.1 \%)$, and hallucinations and other psychotic symptoms in 1 patient $(0.8 \%)$; 32 patients $(27.1 \%)$ discontinued rivastigmine patch for unknown reasons other than ADEs. The main reasons for discontinuation are shown in Table 4.

\section{Discontinuation due to cutaneous application site reactions}

Of the 74 patients who discontinued rivastigmine patch application due to cutaneous application site reactions, the specific reason for discontinuation was contact dermatitis

Table 3 Number of patients who ADEs by rivastigmine dose $(n=209)$

\begin{tabular}{lllll}
\hline Dose & Male & Female & Total & $\begin{array}{l}\text { Frequency } \\
\text { of ADEs (\%) }\end{array}$ \\
\hline $4.5 \mathrm{mg}$ & 10 & 32 & 42 & 20.1 \\
$9.0 \mathrm{mg}$ & 20 & 52 & 72 & 34.4 \\
$13.5 \mathrm{mg}$ & 11 & 21 & 32 & 15.3 \\
$18.0 \mathrm{mg}$ & 20 & 43 & 63 & 30.1 \\
Total & 61 & 148 & 209 & \\
\hline
\end{tabular}

Abbreviation: ADE, adverse drug event. 
Table 4 Main reasons for discontinuing rivastigmine patch application $(n=1 / 8)$

\begin{tabular}{|c|c|c|c|c|}
\hline Main reason & Male & Female & Total & $\begin{array}{l}\text { Frequency of } \\
\text { discontinuing } \\
\text { rivastigmine (\%) }\end{array}$ \\
\hline $\begin{array}{l}\text { Cutaneous application site } \\
\text { reactions }\end{array}$ & 19 & 55 & 74 & 62.7 \\
\hline Gastrointestinal disorders & 2 & 3 & 5 & 4.2 \\
\hline $\begin{array}{l}\text { Metabolic/nutritional } \\
\text { disorders }\end{array}$ & 0 & 0 & 0 & 0 \\
\hline Psychiatric disorders & I & 5 & 6 & 5.1 \\
\hline Nervous system disorders & 0 & 0 & 0 & 0 \\
\hline Other symptoms & 0 & 1 & I & 0.8 \\
\hline Others & 8 & 24 & 32 & 27.1 \\
\hline Total & 30 & 88 & 118 & \\
\hline
\end{tabular}

in 56 patients $(75.7 \%)$, pruritus in 16 patients $(21.6 \%)$, and erythema in 2 patients $(2.7 \%)$ (Table 5$)$.

Among the 74 patients who discontinued rivastigmine patch application due to cutaneous application site reactions, dose at the time of discontinuation was $4.5 \mathrm{mg}$ in 22 patients $(29.7 \%), 9 \mathrm{mg}$ in 37 patients $(50.0 \%), 13.5 \mathrm{mg}$ in 10 patients (13.5\%), and $18 \mathrm{mg}$ in 5 patients (6.8\%). Doses at the time of discontinuation due to cutaneous application site reactions are shown in Table 6 and Figure 2.

\section{Discussion}

We previously conducted studies showing that improving donepezil hydrochloride compliance is effective for ensuring continued application. ${ }^{8,9}$ In the present study, we examined the association between manifestation of ADEs and continued application of the rivastigmine patch in 312 patients. ADEs were observed in $67.0 \%(209 / 312)$ of patients, slightly lower than in the results of safety data from a clinical trial in Japan (in which adverse events were observed in $78.8 \%$ of participants). ${ }^{6}$ However, because the safety data included abnormal values of laboratory investigations in $10.3 \%$ of participants, the frequency of ADEs in the trial and in the present study are considered almost the same.

Contact dermatitis occurred in 99 of 312 patients (31.7\%) in our investigation, but the frequency of contact dermatitis $(25.4 \%)$ indicated on the information for approved drugs in Japan, was also high. Because there was no mention of difference between contact dermatitis and application site edema in pharmacist's medication instruction records, application site edema was included in contact dermatitis in our investigation. But pruritus in 62 of 312 patients $(19.9 \%)$ was lower than the frequency of pruritus $(36.6 \%)$ indicated on information approved drugs in Japan.

Of the 209 patients who developed ADEs, ADEs occurred at the initial dose of $4.5 \mathrm{mg}$ in $20.1 \%$ of those patients, at the next dose of $9 \mathrm{mg}$ in $34.4 \%$ of patients, and at the $13.5 \mathrm{mg}$ dose in $15.3 \%$ of patients. Thus, $\sim 70 \%$ of patients who developed ADEs did so before reaching the maintenance dose of $18 \mathrm{mg}$. These results suggest that when using the

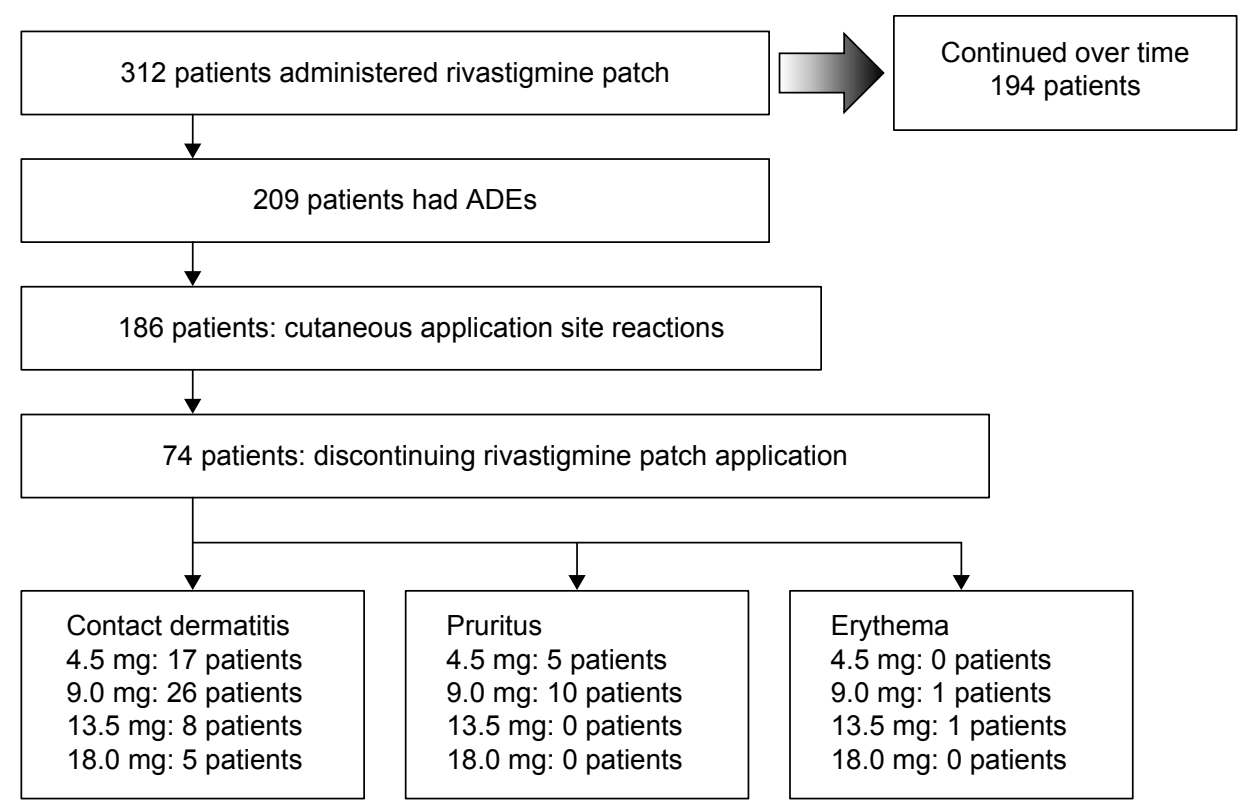

Figure 2 Flowchart of discontinuing rivastigmine patch application due to cutaneous application site reactions. Abbreviation: $A D E$, adverse drug event. 
Table 5 Frequency of specific application site reactions that led to discontinuation $(n=74)$

\begin{tabular}{lllll}
\hline $\begin{array}{l}\text { Main reason for } \\
\text { discontinuation }\end{array}$ & Male & Female & Total & $\begin{array}{l}\text { Frequency of } \\
\text { discontinuing } \\
\text { rivastigmine (\%) }\end{array}$ \\
\hline Contact dermatitis & 15 & 41 & 56 & 75.7 \\
Pruritus & 4 & 12 & 16 & 21.6 \\
Erythema & 0 & 2 & 2 & 2.7 \\
Total & 19 & 55 & 74 & \\
\hline
\end{tabular}

rivastigmine patch, measures to prevent ADEs must be started at the initial use.

Slightly more patients discontinued in our study (37.8\%) compared to Nakamura et al' $\mathrm{s}^{10}$ report, where $23.9 \%$ patients discontinued in the 3 -step titration group. Of the 118 patients who discontinued rivastigmine patch application due to ADEs, 74 patients $(62.7 \%)$ did so due to cutaneous application site reactions; $29.7 \%$ of these patients discontinued application at a dose of $4.5 \mathrm{mg}$, while $50.0 \%$ of patients did so at a dose of $9 \mathrm{mg}$. These results indicate that for some patients, rashes, sores, and other manifestations of contact dermatitis occur even at low doses early in treatment, and thus patients are unable to continue treatment and reach the effective (maintenance) dose.

In a study by Kudo et $\mathrm{al}^{11}$ in which many AD patients demonstrated asteatosis, rivastigmine patch application was considered to increase patients' susceptibility to contact dermatitis. However, 1 week of pretreatment skin care with heparinoid-containing moisturizers improved rivastigmine patch medication persistence; this effect has however been reported to be insufficient. ${ }^{12}$

One conceivable reason that $\mathrm{AD}$ patients are unable to comply with rivastigmine treatment is that they do not understand the objective of patch application and cannot bear application site reactions, and so they remove the patch. Nevertheless, there might be underlying communication

Table 6 Doses at the time of discontinuation due to cutaneous application site reactions $(n=74)$

\begin{tabular}{lllll}
\hline Dose & Male & Female & Total & $\begin{array}{l}\text { Frequency of } \\
\text { discontinuing } \\
\text { rivastigmine (\%) }\end{array}$ \\
\hline $4.5 \mathrm{mg}$ & 5 & 17 & 22 & 29.7 \\
$9.0 \mathrm{mg}$ & 10 & 27 & 37 & 50.0 \\
$13.5 \mathrm{mg}$ & 4 & 6 & 10 & 13.5 \\
$18.0 \mathrm{mg}$ & 0 & 5 & 5 & 6.8 \\
Total & 19 & 55 & 74 & \\
\hline
\end{tabular}

Note: Patch size: $4.5 \mathrm{mg}=2.5 \mathrm{~cm}^{2}, 9.0 \mathrm{mg}=5.0 \mathrm{~cm}^{2}, 13.5 \mathrm{mg}=7.5 \mathrm{~cm}^{2}$, $18.0 \mathrm{mg}=10.0 \mathrm{~cm}^{2}$. problems, for example, AD patients may not notice or complain of erythema, an early symptom of cutaneous application site reactions. These problems suggest that pharmacists should communicate continuously with rivastigmine patch users and their families from the start of application and must confirm the manifestation of dermal symptoms and application site erythema at an early stage. It may be possible to reach the effective dose of rivastigmine and ensure medication persistence with rivastigmine patch application by constantly examining the application site and taking proactive measures to avoid exacerbating contact dermatitis.

Issues for future study include identifying patients and sites susceptible to contact dermatitis, and skin protection measures for such patients. First, it is necessary to examine the general status and the skin at the site in patients who develop cutaneous application site reactions to determine the correlation between skin moisture retention and the manifestation of application site reactions, and to examine the effects of prophylactic application of topical preparations such as steroid hormone-containing ointments and heparinoid-containing moisturizers on the manifestation of rivastigmine patch application site reactions and continuation of treatment. Furthermore, we hope to provide measures for preventing ADEs resulting from rivastigmine patch application, including early detection and treatment of ADEs, and ensuring continued treatment.

\section{Conclusion}

Approximately $60 \%$ of patients who used the rivastigmine patch developed application site reactions, suggesting difficulty in increasing the dose to the effective dose and in continuing application. Pharmacists and other providers can contribute to improving rivastigmine patch continuation rates by observing the status of the skin when patients begin applying the patch and by taking proactive measures to prevent and respond to ADEs.

\section{Disclosure}

The authors report no conflicts of interest in this work.

\section{References}

1. Cabinet Office, Government of Japan. White paper on the aging society. 2017. Available from: http://www8.cao.go.jp/kourei/whitepaper/w-2017/ zenbun/29pdf_index.html. Accessed December 20, 2017.

2. Yamamura K, Watanabe N. Disease-Based Pharmacotherapy for Pharmacists, II. Japanese Society of Pharmaceutical Health Care and Sciences. 2011:53-68.

3. Japanese Society of Neurology Guidelines for Dementia Joint Committee. Guidelines for Dementia 2017: Igaku-Shoin; 2017. 
4. Umegaki H, Itoh A, Suzuki Y, Nabeshima T. Discontinuation of donepezil for the treatment of Alzheimer's disease in geriatric practice. Int Psychogeriatr. 2008;20(4):800-806.

5. Nozawa A, Otani M. Advantages and disadvantages of transdermally delivered drugs unknowable from package inserts alone: rivastigmine. J Pract Pharm. 2013;64(13):3192-3197.

6. Information for approved drugs in Japan: rivastigmine patch. Available from: http://www.info.pmda.go.jp/go/pack/1190700S1029_1_08/. Accessed December 26, 2017.

7. Kuroda A, Hokonohara D, Kurono A, et al. Effectiveness of rivastigmine in Alzheimer's disease as seen by caregivers: Kagoshima Ninchisho Support (KNS) study. J New Rem Clin. 2013;62(10):1824-1831.

8. Nakamura K, Watanabe N, Ohkawa H, et al. Effects on caregiver burden of a donepezil hydrochloride dosage increase to $10 \mathrm{mg}$ /day in patients with Alzheimer's disease. Patient Prefer Adherence. 2014;15(8): 1223-1228.
9. Watanabe N, Yamamura K, Suzuki Y, et al. Pharmacist-based donepezil outpatient consultation service to improve medication persistence. Patient Prefer Adherence. 2012;6:605-611.

10. Nakamura Y, Strohmaier C, Tamura K, et al. A 24-week, randomized, controlled study to evaluate the tolerability, safety and efficacy of 2 different titration schemes of the rivastigmine patch in Japanese patients with mild to moderate Alzheimer's disease. Dement Geriatr Cogn Dis Extra. 2015;5(3):361-374.

11. Kudo C, Yamakawa N, Nakamura N, et al. One-week consecutive pretreatment of moisturizing agent decreases irritant contact dermatitis by rivastigmine patch in the treatment of Alzheimer's disease. J Jpn Soc Early Stage Dement. 2013;6(1):98-102.

12. Ishihama H, Sugamata N, Seo Y, et al. Effects of a heparinoid topical spray for Rivastigmine patch-induced skin reactions. Prog Med. 2016; 36(12):95-99.

Patient Preference and Adherence

\section{Dovepress}

\section{Publish your work in this journal}

Patient Preference and Adherence is an international, peer-reviewed, open access journal that focuses on the growing importance of patient preference and adherence throughout the therapeutic continuum. Patient satisfaction, acceptability, quality of life, compliance, persistence and their role in developing new therapeutic modalities and compounds to optimize clinical outcomes for existing disease states are major areas of interest for the journal. This journal has been accepted for indexing on PubMed Central. The manuscript management system is completely online and includes a very quick and fair peer-review system, which is all easy to use. Visit http://www dovepress.com/testimonials.php to read real quotes from published authors. 